\title{
Impact of Acetylsalicylic Acid on the Clinicopathological Characteristics and Prognosis of Patients with Invasive Breast Cancer
}

\author{
Mehmet A.N. Sendur ${ }^{a}$ Sercan Aksoy ${ }^{b} \quad$ Nuriye Y. Ozdemir ${ }^{a} \quad$ Nurullah Zengin $^{c} \quad$ Kadri Altundag $^{b}$ \\ a Yıldırım Beyazıt University, Department of Medical Oncology, Ankara, Turkey \\ ${ }^{\mathrm{b}}$ Hacettepe University Cancer Institute, Department of Medical Oncology, Ankara, Turkey \\ ${ }^{c}$ Ankara Numune Education and Research Hospital, Department of Medical Oncology, Ankara, Turkey
}

\section{Keywords}

Aspirin · Acetylsalicylic acid · NSAIDs - Breast cancer

\section{Summary}

Background: The impact of acetylsalicylic acid (ASA) on the clinicopathological characteristics of breast cancer has not yet been elucidated in detail; we therefore aimed to investigate the effects of ASA on the clinicopathological characteristics of patients with breast cancer. Patients and Methods: Patients diagnosed with breast cancer were retrospectively analyzed. Breast cancer patients who were taking ASA at the time of breast cancer diagnosis were enrolled as ASA users ( $n=84)$; matching patients with the same age who were not taking ASA were included as control group $(n=890)$. Results: The median age was 56 (range 34-82) years in both groups. ASA users had a significantly lower incidence of grade II-III tumors compared to non-users $(P=0.02)$. The other clinicopathological characteristics and treatment histories were similar in both groups. In patients using ASA, the disease-free survival (DFS) rate was $97.3 \%, 89.4 \%$, and $79.9 \%$ and in non-users it was $94.1 \%, 81.8 \%$, and $70.9 \%$ in the $1 \mathrm{rst}, 3 \mathrm{rd}$, and 5 th year, respectively $(\mathrm{P}=0.01)$. In aspirin users, the overall survival rate was $95.0 \%, 90.6 \%$, and $87.6 \%$ and in non-users it was $98.1 \%, 91.2 \%$, and $85.5 \%$ in the $1 \mathrm{rst}, 3 \mathrm{rd}$, and 5 th year, respectively $(\mathrm{P}=$ 0.50). Conclusion: Using ASA at the time of breast cancer diagnosis was associated with significantly improved DFS in breast cancer patients.

\section{Introduction}

Breast cancer is the most common malignancy, expected to account for $29 \%$ of all new cancer cases among women [1]. Thus, risk reduction strategies and preventive approaches for breast cancer have been attractive for researchers in the recent years. The enzyme cyclooxygenase (COX) rapidly induces inflammation, growth factors, cytokines, and endotoxins, resulting in cell proliferation and carcinogenesis [2]. Prostaglandins also have deleterious effects on carcinogenesis by promoting cell proliferation and angiogenesis [3, 4].

Acetylsalicylic acid (ASA) can interfere with breast cancer carcinogenesis mainly by inhibiting the production of prostaglandins and by inhibiting both the COX-1 and COX-2 isoenzymes [5]. Blocking COX-1 and COX-2 may inhibit breast carcinogenesis via interfering with DNA adduct formation, inhibiting angiogenesis and aromatase expression, and via increased apoptosis [6-9]. Other important ASA-based inhibitory mechanisms of carcinogenesis are the up-regulation of tumor suppressor genes such as those coding for TP53 and Bax and the down-regulation of antiapoptotic genes such as the $\mathrm{Bcl} 2$ gene [10]. Also, ASA can induce cell apoptosis by altered gene transcription, cell cycle arrest, modulation of protein synthesis, and interference with signaling pathways via COX-independent effects [11-14]. Other probable chemopreventive mechanisms of ASA are the inhibition of tumor proliferation by inhibiting the mitochondrial calcium uptake and the reduction of DNA damage by decreasing oxidative stress $[15,16]$. In vitro studies showed that ASA can repair the immune damage caused by radiation therapy for breast cancer [17]. In a mouse model study, treatment with COX inhibitors resulted in less tumor growth [18]. Holmes et al. [19] reported that COX-2 expression in a tumor was associated

\section{KARGER \\ Fax +497614520714 \\ Information@Karger.com}

www.karger.com (c) 2014 S. Karger GmbH, Freiburg

$1661-3791 / 14 / 0094-0261 \$ 39.50 / 0$

Accessible online at:

www.karger.com/brc
Mehmet Ali Nahit Sendur, MD

Yıldırım Beyazıt University

Ankara Atatürk Education and Research Hospital

Department of Medical Oncology

Ankara, Turkey

masendur@yahoo.com.tr 
with higher diagnostic stage and worse breast cancer prognosis in a study of 2,001 patients with invasive breast cancer. An in vitro study showed that the combination of ASA with exemestane compared to exemestane alone increased the response rate in breast cancer cells with high COX-1 and COX-2 expression [20].

Observational studies showed that using ASA for at least 5 years reduces the incidence and mortality of colorectal cancer [21-23]. With regular use of ASA, also the incidences of esophagus, gastric, biliary, lung, ovary, and prostate cancers were reduced [24-26]. In a recently published study, no association was found between the regular use of ASA and nonsteroidal anti-inflammatory drugs (NSAIDs) and the risk of postmenopausal breast cancer [27]. In another recently published study, the large U.S. Cancer Prevention Study II
Nutrition Cohort study among 77,413 women, neither aspirin nor NSAIDs were associated with the incidence of breast cancer [28]. In a Canadian cohort study, it was shown that using ASA at $>100 \mathrm{mg}$ /day may result in a lower risk of breast cancer whereas using ASA at $\leq 100 \mathrm{mg}$ /day did not affect the incidence of breast cancer [29]. In the Women's Health Initiative (WHI) trial, using ASA on alternate days did not show any reduction in any cancer incidence [30]. In another prospective cohort study on 26,580 postmenopausal women, using ASA was associated with a $20 \%$ risk reduction of postmenopausal breast cancer incidence [31]. A recent meta-analysis of 19 cohort studies, 13 case-control studies, and 1 randomized control study showed that regular use of ASA may be associated with a lower breast cancer risk (relative risk $(\mathrm{RR})=0.86)$.

Table 1. Baseline characteristics by ASA use

\begin{tabular}{|c|c|c|c|c|c|}
\hline \multirow[t]{3}{*}{ Characteristic } & \multicolumn{5}{|c|}{ ASA use } \\
\hline & \multicolumn{2}{|c|}{ Yes $(n=84)$} & \multicolumn{3}{|c|}{ No $(\mathrm{n}=890)$} \\
\hline & $\mathrm{n}$ & $\%$ & $\mathrm{n}$ & $\%$ & $P$ value \\
\hline \multicolumn{6}{|l|}{ Age } \\
\hline$\leq 50$ years & 24 & 28.6 & 305 & 34.3 & \multirow[t]{2}{*}{0.33} \\
\hline$>50$ years & 60 & 71.4 & 585 & 65.7 & \\
\hline \multicolumn{6}{|l|}{ Body mass index } \\
\hline$<25.0 \mathrm{~kg} / \mathrm{m}^{2}$ & 14 & 18.2 & 187 & 23.7 & \multirow[t]{3}{*}{0.54} \\
\hline $25.0-29.9 \mathrm{~kg} / \mathrm{m}^{2}$ & 32 & 41.5 & 309 & 39.2 & \\
\hline$\geq 30 \mathrm{~kg} / \mathrm{m}^{2}$ & 31 & 40.3 & 292 & 37.1 & \\
\hline \multicolumn{6}{|l|}{ Smoking } \\
\hline No & 70 & 83.3 & 713 & 80.1 & \multirow[t]{2}{*}{0.48} \\
\hline Yes & 14 & 16.7 & 177 & 19.9 & \\
\hline \multicolumn{6}{|l|}{ Parity } \\
\hline Nulliparous & 4 & 4.8 & 19 & 2.1 & \multirow[t]{2}{*}{0.38} \\
\hline Parous & 80 & 95.2 & 871 & 97.9 & \\
\hline \multicolumn{6}{|l|}{ Menopausal status } \\
\hline Premenopausal & 17 & 20.2 & 217 & 24.6 & \multirow[t]{3}{*}{0.33} \\
\hline Perimenopausal & 3 & 3.6 & 57 & 6.5 & \\
\hline Postmenopausal & 64 & 76.2 & 608 & 69.9 & \\
\hline \multicolumn{6}{|c|}{ Family history of breast cancer } \\
\hline No & 81 & 96.4 & 863 & 97.0 & \multirow[t]{2}{*}{0.86} \\
\hline Yes & 3 & 3.6 & 27 & 3.0 & \\
\hline \multicolumn{6}{|l|}{ Diabetes mellitus } \\
\hline No & 62 & 73.8 & 731 & 82.1 & \multirow[t]{2}{*}{0.07} \\
\hline Yes & 22 & 26.2 & 159 & 17.9 & \\
\hline \multicolumn{6}{|l|}{ Hypertension } \\
\hline No & 32 & 38.1 & 481 & 54.0 & \multirow[t]{2}{*}{0.006} \\
\hline Yes & 52 & 61.9 & 409 & 46.0 & \\
\hline \multicolumn{6}{|l|}{ Hyperlipidemia } \\
\hline No & 67 & 79.8 & 818 & 91.9 & \multirow[t]{2}{*}{0.001} \\
\hline Yes & 17 & 20.2 & 72 & 8.1 & \\
\hline \multicolumn{6}{|c|}{ Hormone replacement therapy } \\
\hline No & 71 & 84.5 & 738 & 85.3 & \multirow[t]{2}{*}{0.87} \\
\hline Yes & 13 & 15.5 & 127 & 14.7 & \\
\hline \multicolumn{6}{|l|}{ Oral contraceptive use } \\
\hline Never & 70 & 83.3 & 681 & 79.0 & \multirow[t]{3}{*}{0.60} \\
\hline $0-12$ months & 9 & 10.7 & 106 & 12.3 & \\
\hline$>12$ months & 5 & 6.0 & 75 & 8.7 & \\
\hline
\end{tabular}




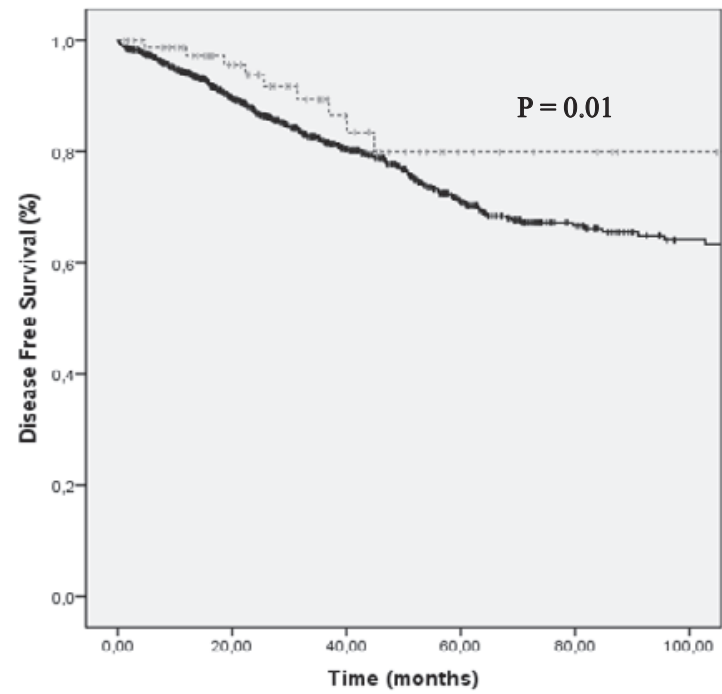

Fig. 1. Analysis of the DFS of ASA users and non-users.

As a result of the published studies and meta-analyses, there were contradictory results regarding the impact of using ASA on the breast cancer risk. But the effects of ASA use on the clinicopathological properties of breast cancer have not yet been elucidated in detail. In this retrospective study, we aimed to investigate the impact of ASA on the demographic and clinicopathological characteristics of breast cancer patients at the time of diagnosis.

\section{Patients and Methods}

Breast cancer patients diagnosed between 2001 and 2013 in our clinic were analyzed retrospectively. A total of 3,000 patients with breast cancer were admitted to our clinic. Breast cancer patients who were taking ASA at the time of breast cancer diagnosis were enrolled as ASA users $(n=84)$, whereas matching patients with the same age who did not use ASA were included as control group $(\mathrm{n}=890)$. Demographic and clinicopathological properties including age, menopausal status, weight, height, breast cancer treatment history, hormonal treatment history, and comorbidities were collected from the medical charts. Tumors were graded according to the modified Bloom-Richardson scoring system and staged according to the tumornode-metastasis (TNM) criteria. The data on estrogen receptor (ER), progesterone receptor (PR), and human epidermal growth factor receptor 2 (HER2)/neu expression were obtained through standard clinical testing, using immunohistochemistry (IHC) for ER and PR and the HercepTest ${ }^{\mathrm{TM}}$ (Dako) for HER2/neu. For the ER and PR, receptor positivity was based on more than $1 \%$ of cells testing positive. Patients were categorized as triple negative if they were negative for ER, PR, and HER2/neu.

\section{Statistical Analysis}

Statistical analyses were performed by using SPSS for Windows version 18.0 (SPSS, Chicago, IL, USA). The baseline characteristics of ASA users were compared with those of non-users by $\chi^{2}$ tests (for categorical variables) or with 2 -sample t-tests (for continuous variables). Tumors with missing values were omitted from the analyses. Kaplan-Meier sur-

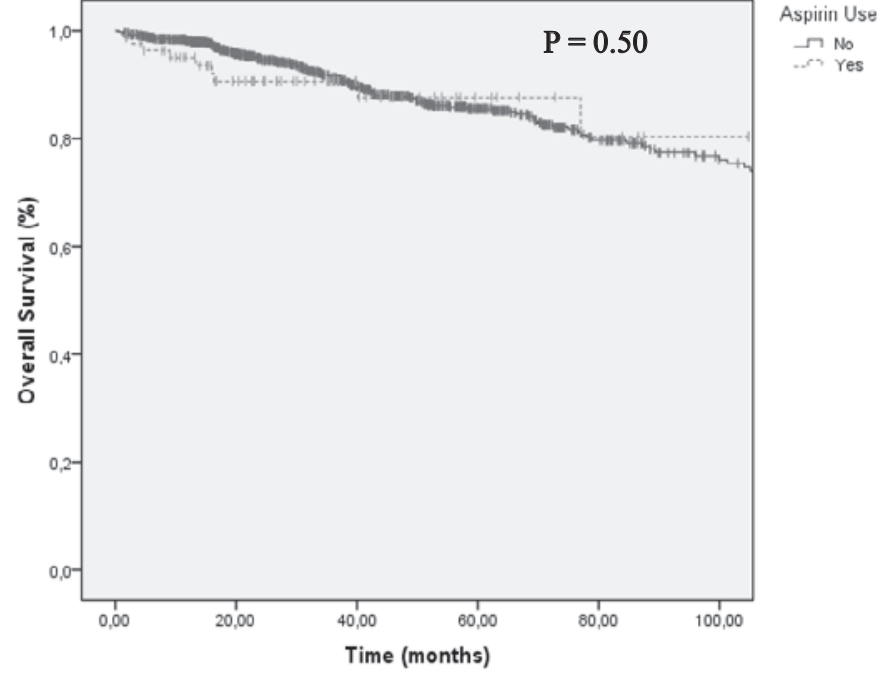

Fig. 2. Analysis of the OS of ASA users and non-users.

vival analysis was carried out for disease-free survival (DFS) and overall survival (OS). The log-rank test was used to examine the statistical significance of the differences observed between the groups. 2-sided $\mathrm{P}$ values of $<0.05$ were considered as statistically significant.

\section{Results}

A total of 974 patients were included to this study. The median age of both the ASA users and non-users was 56 (range 34-82) years. Breast cancer patients who were taking ASA for more than 1 year at the time of breast cancer diagnosis were enrolled as ASA users $(\mathrm{n}=84)$; matching patients with the same age who had no history of using ASA were included as control group $(\mathrm{n}=890)$. The baseline demographic characteristics of the participants are described in table 1 . The frequency of hypertension was found to be significantly higher in the ASA users compared to the non-users (61.9\% vs. $46.0 \%$; $\mathrm{P}=0.006)$. Also hyperlipidemia was found significantly more often in the ASA users compared to the non-users (20.2\% vs. $8.1 \% ; \mathrm{P}=0.001)$. Diabetes mellitus occurred non-significantly more often in the ASA users $(26.2 \%)$ compared to the nonusers $(17.9 \% ; \mathrm{P}=0.07)$. There were no apparent differences in the other baseline demographic characteristics between ASA users and non-users. The median follow-up of this study was 27.4 months.

The baseline tumor characteristics of the participants are described in table 2 . In both groups, the histology of the primary tumor and the type of surgery were similar. Also, in both arms, the rates of lymphovascular invasion, perineural invasion, and extracapsular extension were similar. ASA users had a significantly lower incidence of histological grade II-III tumors compared to non-users $(\mathrm{P}=0.02)$. There were no apparent differences in the baseline tumor size $(\mathrm{P}=0.91)$, lymph node positivity $(\mathrm{P}=0.18)$, and tumor stage $(\mathrm{P}=0.40)$ 
Table 2. Baseline tumor characteristics by ASA use

\begin{tabular}{|c|c|c|c|c|c|}
\hline \multirow[t]{3}{*}{ Characteristics } & \multicolumn{5}{|c|}{ ASA use } \\
\hline & \multicolumn{2}{|c|}{ Yes $(\mathrm{n}=84)$} & \multicolumn{3}{|c|}{ No $(\mathrm{n}=890)$} \\
\hline & $\mathrm{n}$ & $\%$ & $\mathrm{n}$ & $\%$ & $P$ value \\
\hline \multicolumn{6}{|l|}{ Type of surgery } \\
\hline None & 0 & 0 & 10 & 1.2 & 0.45 \\
\hline Breast-conserving surgery & 20 & 25.0 & 244 & 28.8 & \\
\hline Modified radical mastectomy & 60 & 75.0 & 592 & 70.0 & \\
\hline \multicolumn{6}{|l|}{ Histology of the primary tumor } \\
\hline Invasive ductal carcinoma & 58 & 70.7 & 611 & 69.5 & 0.27 \\
\hline Invasive lobular carcinoma & 8 & 9.8 & 55 & 6.3 & \\
\hline Mixed & 7 & 8.5 & 119 & 13.5 & \\
\hline Others & 9 & 11.0 & 94 & 10.7 & \\
\hline \multicolumn{6}{|l|}{ ER } \\
\hline Positive & 63 & 75.0 & 640 & 73.2 & 0.61 \\
\hline Negative & 21 & 25.0 & 250 & 26.8 & \\
\hline \multicolumn{6}{|l|}{$\mathrm{PR}$} \\
\hline Positive & 61 & 72.6 & 593 & 66.6 & 0.27 \\
\hline Negative & 23 & 27.4 & 297 & 33.4 & \\
\hline \multicolumn{6}{|l|}{ HER2 } \\
\hline Positive & 14 & 16.7 & 144 & 16.2 & 0.74 \\
\hline Negative & 70 & 83.3 & 746 & 83.8 & \\
\hline \multicolumn{6}{|l|}{ Triple negative } \\
\hline Yes & 8 & 8.5 & 112 & 12.6 & 0.70 \\
\hline No & 76 & 91.5 & 778 & 87.4 & \\
\hline \multicolumn{6}{|l|}{ Grade } \\
\hline I & 19 & 25.0 & 100 & 13.4 & 0.02 \\
\hline II & 31 & 40.8 & 364 & 48.6 & \\
\hline III & 26 & 34.2 & 285 & 38.1 & \\
\hline \multicolumn{6}{|l|}{ Lymphovascular invasion } \\
\hline Positive & 20 & 23.8 & 211 & 23.7 & 0.98 \\
\hline Negative & 64 & 76.2 & 679 & 76.3 & \\
\hline \multicolumn{6}{|l|}{ Perineural invasion } \\
\hline Positive & 15 & 17.9 & 107 & 12.0 & 0.12 \\
\hline Negative & 69 & 82.1 & 783 & 88.0 & \\
\hline \multicolumn{6}{|l|}{ Extracapsular extension } \\
\hline Positive & 6 & 7.1 & 91 & 10.2 & 0.44 \\
\hline Negative & 78 & 92.9 & 759 & 89.8 & \\
\hline \multicolumn{6}{|l|}{$\mathrm{T}$ stage at diagnosis } \\
\hline $\mathrm{T} 1$ & 25 & 31.2 & 298 & 34.9 & 0.91 \\
\hline $\mathrm{T} 2$ & 43 & 53.8 & 415 & 48.5 & \\
\hline $\mathrm{T} 3$ & 9 & 11.3 & 112 & 13.1 & \\
\hline $\mathrm{T} 4$ & 3 & 3.7 & 30 & 3.5 & \\
\hline \multicolumn{6}{|l|}{ Lymph node status } \\
\hline N0 & 39 & 46.4 & 438 & 49.3 & 0.18 \\
\hline $\mathrm{N} 1$ & 23 & 27.4 & 242 & 27.2 & \\
\hline $\mathrm{N} 2$ & 15 & 17.9 & 101 & 11.3 & \\
\hline N3 & 7 & 8.3 & 109 & 12.2 & \\
\hline TNM stage & & & & & \\
\hline I & 15 & 19.0 & 208 & 24.0 & 0.40 \\
\hline II & 37 & 46.8 & 362 & 41.7 & \\
\hline III & 23 & 29.1 & 211 & 24.3 & \\
\hline IV & 4 & 5.1 & 87 & 10.0 & \\
\hline Adjuvant chemotherapy & & & & & \\
\hline Yes & 50 & 59.5 & 584 & 65.6 & 0.37 \\
\hline No & 34 & 40.5 & 306 & 34.4 & 0.37 \\
\hline Adjuvant radiotherapy & & & & & \\
\hline Yes & 53 & 63.1 & 549 & 61.7 & 0.98 \\
\hline No & 31 & 36.9 & 341 & 38.3 & \\
\hline Adjuvant hormonal treatment & & & & & \\
\hline Yes & 70 & 83.3 & 665 & 74.7 & 0.21 \\
\hline No & 14 & 16.7 & 225 & 25.3 & \\
\hline
\end{tabular}


between the 2 groups. ER positivity was observed in $75.0 \%$ and $73.2 \%$ of the ASA users and non-users, respectively ( $\mathrm{P}=$ 0.61 ). Regarding the PR status, $72.6 \%$ and $66.6 \%$ positivity were observed in the ASA users and non-users, respectively $(\mathrm{P}=0.27)$. In the subgroup analysis, $65.0 \%$ and $62.5 \%$ of the patients had both ER and PR positivity in case of ASA users and non-users, respectively $(\mathrm{P}=0.28)$. Only ER positivity was found in $3.6 \%$ of the ASA users whereas it was found in $8.5 \%$ of the non-users $(\mathrm{P}=0.14)$. Only $\mathrm{PR}$ positivity was found at similar frequencies in the 2 groups $(3.1 \%$ vs. $5.3 \% ; \mathrm{P}=0.76)$. HER2 positivity $(\mathrm{P}=0.74)$ and the incidence of triple-negative tumors $(P=0.70)$ were similar in both groups. The treatment histories with adjuvant chemotherapy and radiotherapy were also similar and not significantly different between the ASA users and the non-users. In both groups, adjuvant chemotherapy and radiotherapy were used similarly. Hormonal treatment was used in $83.3 \%$ and $74.7 \%$ of the ASA users and non-users, respectively $(\mathrm{P}=0.21)$.

In the ASA users, the DFS rates were $97.3 \%, 89.4 \%$, and $79.9 \%$, whereas they were $94.1 \%, 81.8 \%$, and $70.9 \%$ in the non-users in the $1 \mathrm{rst}, 3 \mathrm{rd}$, and 5 th year, respectively $(\mathrm{P}=0.01)$ (fig. 1). In the subgroup analysis, no effects of hypertension (P $=0.54)$, hyperlipidemia $(\mathrm{P}=0.14)$, or diabetes mellitus $(\mathrm{P}=$ $0.69)$ were found on the risk of recurrence. The median OS could not be obtained due to the low number of events and the short follow-up period. The OS rates of the ASA users and non-users were $95.0 \%, 90.6 \%$, and $87.6 \%$ and $98.1 \%$, $91.2 \%$, and $85.5 \%$ the $1 \mathrm{rst}, 3 \mathrm{rd}$, and 5 th year, respectively $(\mathrm{P}=$ $0.50)$ (fig. 2).

\section{Discussion}

In this study, we showed that using ASA at the time of breast cancer diagnosis corresponded with a significantly lower incidence of histological grade II-III tumors compared to non-users. Other clinical and pathological features were similar between ASA users and non-users. Hormone receptor positivity was also similar in both groups. The DFS rate was significantly better in ASA users compared to non-users, but the difference in the OS rate was not statistically significant. Despite the higher rate of hypertension, hyperlipidemia, and diabetes mellitus seen in ASA users, no effect on the DFS was found in the subgroup analysis of these comorbidities.

Evidence from published studies showed that regular use of ASA for at least 5 years is associated with a risk reduction of colorectal cancer by $20-30 \%$ [32]. For other gastrointestinal system cancers, the risk reduction was reported as approximately $30 \%$ by regular ASA use, whereas the risk reduction was modest in both breast and prostate cancer [32]. Due to the heterogeneity of the case-control and cohort studies in breast cancer, no association was found between the dose and duration of ASA use. Thus, the absolute duration and the optimal dose of ASA for the prevention of breast cancer are still not known.
Both preclinical and epidemiologic data support the notion that ASA has anticancer activity in the case of breast cancer. Preclinical studies showed that adding ASA to aromatase inhibitors can increase the response rate compared to singleagent aromatase inhibitors in breast cancer cells with high COX-1 and COX-2 expression [20]. Treatment of wild-type mice with a selective COX-2 inhibitor showed a reduction of tumor growth and additionally a reduction of vascular endothelial growth factor (VEGF) production by 92\% [18]. Hudson et al. [33] reported significantly lower levels of serum estradiol in postmenopausal breast cancer patients who used ASA and NSAIDs compared to non-users. In our study, we found that the DFS rate was significantly improved with using ASA, but the OS rate was not significantly improved. Consistent with the results of our study, Rothwell et al. [34], in an observational study of randomized controlled trials, reported that daily use of ASA reduced the risk of all distant metastases of all cancer types. Compared to our study, the Nurses' Health Study with 4,164 participants showed that using ASA after breast cancer diagnosis was associated with decreased rates of death and distant recurrence of breast cancer [35]. Previous studies also demonstrated a decreased risk of recurrence of early breast cancer with using NSAIDs other than ASA [36]. In another study, Li et al. [37] reported that using pre-diagnostic ASA or NSAIDs was not associated with survival following breast cancer diagnosis like in our study.

There is limited data about the association of COX-2 expression with ER, PR, and HER2 expression. Thus, using ASA seems to have an effect on the risk of both ER-positive and -negative tumors. Zhang et al. [27] reported that ASA had no role in breast cancer molecular subtypes. In the subgroup analyses of the Women's Health Study (WHS), no effect of ASA was found on the tumor size, lymph node metastasis, histology, the hormonal status, and the grading [38]. In another study, the use of ASA was associated with a reduced risk of breast cancer, with no effects on molecular subtypes [39]. In comparison to previous studies, ASA users in our study had a significantly lower incidence of histological grade II-III tumors, but no other effect on the pathological properties was found.

Our study has some limitations due to the retrospective design. In our study, there is no data about the definite time of the beginning of ASA use and the exact dosage of ASA. And there is no data on whether the patients continued to use ASA after breast cancer diagnosis. It is not possible to estimate the dose-response effect or the duration of ASA use in our breast cancer patients. The information on the ASA usage was self-reported. Also, in our study, we do not have data on whether or not the patients used additional NSAIDs for chronic pain. Thus, we do not know whether NSAIDs had an additive effect. In our study, we observed a DFS advantage by using ASA, but this advantage was not observed for OS. This controversy can be explained by significantly higher comorbidities in the group of ASA users. Another limitation of our 
study is that ASA users may be more likely to use mammography screening programs than non-users. Recent studies show that both angiotensin and beta-blockage may have an important role in breast cancer carcinogenesis [40, 41]. Thus, the unspecified usage of angiotensin-converting enzyme inhibitors and beta-blockers may have had additive effects to those of ASA usage.

In conclusion, despite the contradictory results regarding ASA use and breast cancer incidence, using ASA at the time of breast cancer diagnosis was associated with an improved
DFS in our study. ASA users have a significantly lower incidence of histological grade II-III tumors, but no effect was found on other clinicopathological properties. This retrospective study requires further prospective confirmative cohort studies.

\section{Disclosure Statement}

The authors declare no potential conflicts of interest.

\section{References}

1 Siegel R, Naishadham D, Jemal A: Cancer statistics, 2013. CA Cancer J Clin 2013;63:11-30.

2 Herschman HR: Prostaglandin synthase 2. Biochim Biophys Acta 1996;1299:125-140.

$\checkmark 3$ Chell S et al.: Mediators of PGE2 synthesis and signalling downstream of COX-2 represent potentia targets for the prevention/treatment of colorectal cancer. Biochim Biophys Acta 2006;1766:104-119.

4 Wang D, Dubois RN: Prostaglandins and cancer. Gut 2006;55:115-122.

5 Davies G et al.: Cyclooxygenase-2 (COX-2), aromatase and breast cancer: a possible role for COX-2 inhibitors in breast cancer chemoprevention. Ann Oncol 2002;13:669-678

6 Abbadessa $\mathrm{G}$ et al.: The aspirin metabolite, salicylate, inhibits 7,12-dimethylbenz[a]anthraceneDNA adduct formation in breast cancer cells. Int $\mathrm{J}$ Oncol 2006;28:1131-1140.

7 Masferrer JL et al.: Antiangiogenic and antitumor activities of cyclooxygenase-2 inhibitors. Cancer Res 2000;60:1306-1311.

8 Leahy KM et al.: Cyclooxygenase- 2 inhibition by celecoxib reduces proliferation and induces apoptosis in angiogenic endothelial cells in vivo. Cancer Res 2002;62:625-631.

-9 Shapiro CL: Aromatase inhibitors and bone loss: risks in perspective. J Clin Oncol 2005;23:4847-4849.

10 Bellosillo B et al.: Aspirin and salicylate induce apoptosis and activation of caspases in B-cell chronic lymphocytic leukemia cells. Blood 1998; 92:1406-1414.

11 Dong $\mathrm{Z}$ et al.: Inhibition of activator protein 1 activity and neoplastic transformation by aspirin. J Biol Chem 1997;272:9962-9970.

$12 \mathrm{Lu} \mathrm{M}$ et al.: Aspirin sensitizes cancer cells to TRAIL-induced apoptosis by reducing survivin levels. Clin Cancer Res 2008;14:3168-3176.

$13 \mathrm{Xu}$ XM et al.: Suppression of inducible cyclooxygenase 2 gene transcription by aspirin and sodium salicylate. Proc Natl Acad Sci USA 1999;96:5292-5297.

14 Pillinger $\mathrm{MH}$ et al.: Modes of action of aspirin-like drugs: salicylates inhibit Erk activation and integrin-dependent neutrophil adhesion. Proc Natl Acad Sci USA 1998;95:14540-14545.

15 Nunez L et al.: Cell proliferation depends on mitochondrial $\mathrm{Ca} 2+$ uptake: inhibition by salicylate. J Physiol 2006;571(pt 1):57-73.
16 Drew JE et al.: Salicylic acid modulates oxidative stress and glutathione peroxidase activity in the rat colon. Biochem Pharmacol 2005;70:888-893.

17 Blomgren $\mathrm{H}$ et al.: In vitro capacity of various cyclooxygenase inhibitors to revert immune suppression caused by radiation therapy for breast cancer. Radiother Oncol 1990;19:329-335.

18 Williams CS et al.: Host cyclooxygenase-2 modulates carcinoma growth. J Clin Invest 2000;105:1589-1594.

19 Holmes MD et al.: COX-2 expression predicts worse breast cancer prognosis and does not modify the association with aspirin. Breast Cancer Res Treat 2011;130:657-662.

$20 \mathrm{Hu}$ LX et al.: Synergistic effects of exemestane and aspirin on MCF-7 human breast cancer cells. Asian Pac J Cancer Prev 2012;13:5903-5908.

21 Rothwell PM et al.: Long-term effect of aspirin on colorectal cancer incidence and mortality: 20-year follow-up of five randomised trials. Lancet 2010; 376:1741-1750.

22 Rothwell PM et al.: Effect of daily aspirin on longterm risk of death due to cancer: analysis of individual patient data from randomised trials. Lancet 2011;377:31-41.

23 Flossmann E, Rothwell PM: Commentary: aspirin and colorectal cancer an epidemiological success story. Int J Epidemiol 2007;36:962-965.

24 Algra AM, Rothwell PM: Effects of regular aspirin on long-term cancer incidence and metastasis: a systematic comparison of evidence from observational studies versus randomised trials. Lancet Oncol 2012;13:518-527.

25 Elwood PC et al.: Aspirin, salicylates, and cancer. Lancet 2009;373:1301-1309.

26 Gonzalez-Perez A, Garcia Rodriguez LA, LopezRidaura R: Effects of non-steroidal anti-inflammatory drugs on cancer sites other than the colon and rectum: a meta-analysis. BMC Cancer 2003;3:28.

27 Zhang $\mathrm{X}$ et al.: Use of aspirin, other nonsteroidal anti-inflammatory drugs, and acetaminophen and postmenopausal breast cancer incidence. J Clin Oncol 2012;30:3468-3477.

28 Jacobs EJ et al.: Daily aspirin use and cancer mortality in a large US cohort. J Natl Cancer Inst 2012; 104:1208-1217.
29 Rahme E et al.: Association between frequent use of nonsteroidal anti-inflammatory drugs and breast cancer. BMC Cancer 2005;5:159.

30 Cook NR et al.: Low-dose aspirin in the primary prevention of cancer: the Women's Health Study: a randomized controlled trial. JAMA 2005;294:47-55.

31 Bardia A et al.: Effect of aspirin and other NSAIDs on postmenopausal breast cancer incidence by hormone receptor status: results from a prospective cohort study. Breast Cancer Res Treat 2011;126: 149-155.

32 Bosetti C et al.: Aspirin and cancer risk: a quantitative review to 2011. Ann Oncol 2012;23:1403-1415.

33 Hudson AG et al.: Nonsteroidal anti-inflammatory drug use and serum total estradiol in postmenopausal women. Cancer Epidemiol Biomarkers Prev 2008;17:680-687.

34 Rothwell PM et al.: Effect of daily aspirin on risk of cancer metastasis: a study of incident cancers during randomised controlled trials. Lancet 2012; 379:1591-1601.

35 Holmes MD et al.: Aspirin intake and survival after breast cancer. J Clin Oncol 2010;28:1467-1472.

36 Kwan ML et al.: NSAIDs and breast cancer recurrence in a prospective cohort study. Cancer Causes Control 2007;18:613-620.

$37 \mathrm{Li} \mathrm{Y}$ et al.: Use of nonsteroidal anti-inflammatory drugs and survival following breast cancer diagnosis. Cancer Epidemiol Biomarkers Prev 2012;21: 239-242.

38 Zhang SM et al.: Low-dose aspirin and breast cancer risk: results by tumour characteristics from a randomised trial. Br J Cancer 2008;98:989-991.

39 Brasky TM et al.: Non-steroidal anti-inflammatory drugs (NSAIDs) and breast cancer risk: differences by molecular subtype. Cancer Causes Control 2011;22:965-975.

40 Powe DG et al.: Beta-blocker drug therapy reduces secondary cancer formation in breast cancer and improves cancer specific survival. Oncotarget 2010; 1:628-638.

41 George AJ, Thomas WG, Hannan RD: The reninangiotensin system and cancer: old dog, new tricks. Nat Rev Cancer 2010;10:745-759. 